\title{
How Do Students Revisit School Mathematics in Modular Arithmetic? Conditions and Affordances of the Transition to Tertiary Mathematics with a Focus on Learning Processes
}

\author{
Alexander Schüler-Meyer ${ }^{1}$ (D)
}

Published online: 8 March 2019

(C) The Author(s) 2019

\begin{abstract}
In the transition from secondary to tertiary mathematics, students try to participate in tertiary mathematics by replicating familiar school mathematical discourses. The objective of this case study is to investigate the conditions and affordances under which students proceed from familiar school mathematical discourses to new, tertiary discourses with a specific perspective on learning processes. The study was located in an upper secondary transition course in a teaching unit on elementary number theory in which highly proficient students in their penultimate year of schooling participated. The main finding is that there was not a linear progression towards the intended tertiary mathematical discourse of modular multiplication but a coexistence of two discourses developing in parallel: the intended tertiary discourse and a continuation of school mathematical discourses. Students see these two discourses as the same, connected by the same perceived aim of searching for patterns. Further hindering discursive development are utterances, in which elements of the intended tertiary discourse (words and representations) are used superfluously, so that elementary/secondary utterances appear to be tertiary. These findings illustrate the need to explicate and address metanarratives. Metanarratives can connect two discourses developing in parallel in ways that, in this case, hinder discursive development towards the intended tertiary discourse.
\end{abstract}

Keywords Secondary-tertiary transition - Elementary number theory · Commognition · Secondary discourse $\cdot$ Tertiary discourse

Alexander Schüler-Meyer

A.k.schuelermeyer@tue.nl

1 Eindhoven School of Education ESoE, Eindhoven University of Technology, PO Box 513, 5600 MB Eindhoven, The Netherlands 


\section{Introduction}

The transition from secondary to university mathematics is difficult for many students (De Guzmán et al. 1998; Thomas et al. 2015). There are many reasons for these difficulties: One of the most relevant is the changing nature of mathematical practices and discourses (e.g., defining and proving, see Selden 2012; Zandieh and Rasmussen 2010; de Guzmán et al. 1998; Gueudet 2008; Alcock and Simpson 2002; Tall 1991). When engaging in new tertiary discourses, students need to revisit or even relearn their school mathematical knowledge (Sfard 2014). During this revisiting of familiar secondary mathematical objects in an unfamiliar tertiary context, students often fall back to their secondary notions of these objects (Nardi et al. 2014; Praslon 1999).

The problem of students falling back to secondary mathematical notions in transition raises the issue of how to design transition courses to revisit school knowledge in order to foster students' knowledge of it in new, tertiary ways. There has been little research on the learning processes involved in relearning school knowledge as tertiary knowledge (Schüler-Meyer 2018). Hence, the objective of this study is to investigate the conditions and affordances under which students come to know their previous school knowledge in new, tertiary ways, with a specific perspective on learning processes. To accomplish this, this study employs a commognitive framework (Sfard 2008) to show that an elementary/secondary discourse and an intended tertiary discourse can develop in parallel in a classroom, leading to latent conflicts in the students' communications, for example, in regard to the use of representations.

This study investigates a transition-course classroom where students revisit their knowledge of multiplication and division with remainders in an elementary number theoretical discourse on modular multiplication with module 10 (multiplication table given in Fig. 1; Leuders 2016). The second and third sections outline the theoretical foundation for this study. The fourth section presents the methodology and the

\begin{tabular}{|c|c|c|c|c|c|c|c|c|c|c|}
\hline$\cdot$ & 1 & 2 & 3 & 4 & 5 & 6 & 7 & 8 & 9 & 10 \\
\hline 1 & 1 & 2 & 3 & 4 & 5 & 6 & 7 & 8 & 9 & 0 \\
\hline 2 & 2 & 4 & 6 & 8 & 0 & 2 & 4 & 6 & 8 & 0 \\
\hline 3 & 3 & 6 & 9 & 2 & 5 & 8 & 1 & 4 & 7 & 0 \\
\hline 4 & 4 & 8 & 2 & 6 & 0 & 4 & 8 & 2 & 6 & 0 \\
\hline 5 & 5 & 0 & 5 & 0 & 5 & 0 & 5 & 0 & 5 & 0 \\
\hline 6 & 6 & 2 & 8 & 4 & 0 & 6 & 2 & 8 & 4 & 0 \\
\hline 7 & 7 & 4 & 1 & 8 & 5 & 2 & 9 & 6 & 3 & 0 \\
\hline 8 & 8 & 6 & 4 & 2 & 0 & 8 & 6 & 4 & 2 & 0 \\
\hline 9 & 9 & 8 & 7 & 6 & 5 & 4 & 3 & 2 & 1 & 0 \\
\hline 10 & 0 & 0 & 0 & 0 & 0 & 0 & 0 & 0 & 0 & 0 \\
\hline
\end{tabular}

Fig. 1 Ludwig's multiplication table for multiplication modulo 10 
teaching-learning intervention on elementary number theory being investigated. The fifth section illustrates the main results of this paper, namely, the commognitive conflict of the eventually-to-be-shared-discourse and its causes, in three episodes.

\section{Problems in Transitioning from Secondary to Tertiary Mathematics}

Students' difficulties in learning processes in transition can be conceptualized as the students' attempts to communicate in secondary discourses while being engaged in tertiary discourses. Nardi et al. (2014) investigated a case where a lecturer simultaneously evoked an algebraic and geometric notion of the derivative in order to decide on a course of action, while students wanted to calculate the derivative (see also Stadler 2011). Thoma and Nardi (2017) illustrate how unresolved commognitive conflicts result in errors as the students communicate in secondary discourses and, because of this, do not specify the nature of variables. Taking a synthesizing perspective, Sfard (2014) argues that the "new [tertiary] discourse is incommensurable with the former [secondary] one, and this means that whatever the student knew before must now become known in a different way" (p. 201). In summary, in transition, conflicts in the communication between discursants occur because the teacher's tertiary discourse and the students' secondary discourses are incommensurable, that is, incompatible in the use of keywords or representations or in their patterned activities (Sfard 2008).

\section{Transitions in Elementary Number Theory}

Elementary number theory as a tertiary subject is accessible to transition students because objects such as multiples and divisibility are familiar to students from elementary mathematics, and representations can give insights into its complex problems (Morselli 2006; Zazkis 2007; de Oliveira 2015; Toh et al. 2014; Zazkis and Gadowsky 2001). Because of its accessibility, elementary number theory allows for three different avenues towards tertiary mathematics. First, students can be engaged in tertiary mathematical practices such as formulating hypotheses, testing conjectures, investigating patterns and understanding proofs (Zazkis and Campbell 2006). Second, students can engage in objectified discourses by progressing from a procedural understanding of divisibility (the action of division) to an object notion (an entity with certain properties and relations) by investigating number examples (Zazkis and Campbell 1996). Third, students can appreciate more formal representations by using word variables for geometrical patterns (Papadopoulos and Iatridou 2010; Iatridou and Papadopoulos 2010). Such formal representations are "natural and relatively benign" because of their closeness to integer arithmetic (Zazkis and Campbell 2006, p. 2).

While elementary number theory is accessible, there are also obstacles that may emerge when students' transition to it. When revisiting elementary processes/objects, they can become "rudimentary and fragile," meaning that students fall back on operations and see few relations to other processes/objects. This can be plausibly explained by unresolved problems of understanding in the early years of schooling (Campbell 2002). For example, students perceive evenness as being related to the last digit of a number, and do not relate it to prime factorization of numbers (Zazkis 1998), 
or they associate divisibility with carrying out a division (Zazkis 2011) and grasp it with linguistic metaphors such as "fitting in" (Zazkis 2002, also Smith 2006). A more elaborate understanding of divisibility as an object requires students to see divisibility as a relation between numbers connected to multiplicative structures (Zazkis and Campbell 1996). Overcoming these obstacles requires a goal-oriented and careful work with number examples (ibid.), the use of representations that highlight relevant features (Zazkis and Gadowsky 2001), and fostering a conceptual understanding of the revisited processes/objects from the early school years (Zazkis 2011).

\section{Transition as Development of Discourses}

The transition to tertiary mathematics is here conceptualized with the theory of Commognition (Sfard 2008) where "learning mathematics. .. is initiation into a discourse. .." (Nardi et al. 2014, p. 184). A discourse is a

special type of communication made distinct by its repertoire of admissible actions and the way these actions are paired with re-actions; every discourse defines its own community of discourse; discourses in language are distinguishable by their vocabularies, visual mediators, routines, and endorsed narratives. (Sfard 2008, p. 297)

A discursive perspective on learning in transition is powerful in highlighting commognitive conflicts stemming from the discursants' engagement in different discourses. A commognitive conflict occurs when discursants try to communicate across incommensurable discourses (Sfard 2008), which leads to dysfunctional communications and prevents learning. In transition, these incommensurable discourses could be an elementary and a tertiary discourse, where students might engage in elementary discourses of multiplication while the teacher and tasks communicate in a tertiary discourse of elementary number theory. Hence, conditions and affordances of discursive development will manifest in commognitive conflicts.

In transition courses, commognitive conflicts will unfold in learning processes over the course of the development of a discourse from elementary/secondary school discourses towards the intended tertiary discourses. The development of discourses can occur at the object level and at the meta-level:

- At the object level, development is the growth of the discourse in regard to the "number and complexity" of endorsed narratives and routines, where narratives "describe objects and processes as well as relationships among those" (Sfard 2008, p. 300). Object-level development is about exploring "regularities in the behavior of objects" (Sfard 2008, p. 300), which leads to new and more complex narratives about these objects. For example, the discourse about multiplication modulo 10 can be grown by also exploring the multiplication modulo 8 or by combining it with the addition modulo 8 to arrive at more complex operations (see Sfard 2008).

- At the meta-level, development occurs by a "change in the meta-rules of the discourse" (Sfard 2008, p. 300). Meta-rules "speak about the actions of the [participants in the discourse], not about the behavior of mathematical objects" (Sfard 2008, p. 201). Meta-level development establishes a meta-level on the object-level discourse, in this case about modular multiplication, by defining 
patterns in the activity of the discursants (Sfard 2008). For example, narratives that establish commutativity would be regarded as a meta-level development, because commutativity establishes a patterned way of the activity of multiplying. It would also be regarded a meta-level development when students change the meta-rule 'one can make inferences about divisibility by dividing' towards the meta-rule 'one can make inferences about divisibility with the prime factorization' (see Transitions in Elementary Number Theory Section), as both rules are about patterns in the activity of modular multiplication. As a result of meta-level developments, words can be used in new ways that are incommensurable with the previous discourse.

The transition towards the tertiary discourse of elementary number theory requires meta-level developments, as the patterns in the activities of elementary multiplication are not compatible to the new patterns of modular multiplication.

\section{Research Questions}

Within commognition, conditions and affordances of coming to know previous school knowledge in new, tertiary ways are manifest in commognitive conflicts in the development of the classroom discourse, on both the object level and the meta-level. Accordingly, this study investigates the following research questions in the context of a transition course on elementary number theory:

RQ1: What commognitive conflicts occur in such a developmental perspective?

RQ2: How do these come into existence when students revisit familiar elementary/ secondary objects and come to know them in new, tertiary ways?

\section{Further Theoretical Foundations for the Developmental Perspective}

From the students' perspectives, the nature of the intended tertiary discourse is yet unfolding, and mathematics is known by way of secondary discourses. The intended tertiary discourse is accessible through mathematical tasks and the expert teacher (Sfard 2014), but also through an unwritten learning-teaching agreement, which gives direction to the classroom communicational activities. This agreement is continually updated to reflect the current shared knowledge about whose discourse is eventually to be shared:

All the participants of the learning-teaching process need to be of one mind with regard to (a) whose discourse is to be eventually shared, (b) who needs to act as the teacher and who as a learner, and (c) what is the expected form, mechanism and pace of the learning process. (Sfard 2015, p. 136)

In transition, this agreement is especially under scrutiny, because students engage, by the very nature of a transition course, in a discourse that develops in unfamiliar ways. Accordingly, the development to a tertiary discourse is here not only investigated in terms of discursive object level and meta-level developments (Transition as Development of Discourses Section), but also from the perspective of how an "eventually-to-be-shared discourse" emerges out of the individual communicative actions of the discursants. In this 
way, discursive development can be grasped as a dynamic process influenced by both the students' perceptions of the intended discourse and the actual "developmental status" of the classroom discourse. To conceptualize discursive development from this perspective, new constructs are introduced to the theory of commognition.

The first construct is discursive variation. Discursive variation accounts for the phenomenon that a discourse's object rules and meta-rules are reiterated and might not change much over time. In other words, it might be that discursants develop variations of narratives and routines that have been established previously. From the students' perspectives, these could seem to be developments of the discourse. This can result in commognitive conflicts of variation, where the students' reiteration of elementary or secondary object rules and meta-rules prevents the alignment of the intended tertiary discourse and the students' discourse. For example, in the exploration of the multiplication table (Fig. 1), the students utter variations of elementary narratives of odd and even numbers.

The second construct is the metanarrative. A metanarrative is a narrative that defines patterns in the discursants' activities of producing narratives (Lyotard 1984; compare also with definition of the metadiscursive rule; Sfard 2008). In other words, metanarratives are the themes behind the individual students' narratives. A metanarrative's function is to assemble single narratives into a coherent whole for the individual student. As such, metanarratives can be informed by past experiences of producing narratives, especially those where narratives should align with institutions or cultural norms. For example, a metanarrative such as "in the end, the teacher will give the correct answer" will establish that students produce narratives that aim at the teacher's approval. Thus, a metanarrative guides a student's communicative actions towards the individually perceived eventually-to-be-shared discourse.

In a transition course where students from different classrooms come together in a new learning group, different discourses will compete and interact with each other, for example, discourses of different classrooms, discourses of different groups during group work, and the discourse of the teacher who comes from a university mathematical background. Following Bakhtin (1981), this is theorized as heteroglossia, the principle that at any given moment different discourses interact and influence a classroom discourse's development. Hence, there is a play of individual discursive actions, each proposing a different narrative, and in this play, these narratives compete to be endorsed by the others, so that they become part of the discourse that is to be shared eventually. In other words, narratives can exert centripetal and centrifugal forces in relation to the intended discourse (Bakhtin 1981).

- Communicative actions exert a centrifugal force towards continuing secondary discourses as the eventually-to-be-shared discourse when they use elements of the intended tertiary discourse (such as keywords and visual mediators) in a supplementary way and express secondary, everyday, or non-viable narratives. A supplementary use of keywords means that the narrative would still be endorsable to the others without these keywords or that the keyword is used as a label to signify that something should be recognized as belonging to the intended discourse. Narratives are regarded as secondary or everyday when they are endorsable in such discourses; they are non-viable if they are not endorsable by experts. For example, the utterance "If one takes two times modulo 5, one has modulo 10" (Task 2, classroom discussion, Edith, T75-80) is secondary, because it could be endorsed in an 
elementary discourse if the keyword "modulo" is omitted. Hence, it exerts a centrifugal force. Centrifugal forces appear to other discursants as being part of the intended discourse by using some of its elements, but their narratives are variations of already endorsed secondary narratives or are even non-viable. Hence, in terms of the learningteaching agreement, they stabilize and perpetuate familiar (secondary) discourses as eventually-to-be-shared discourses, this way hindering discursive development.

- Communicative actions exert a centripetal force towards establishing the intended tertiary discourse when they use keywords in previously accepted ways and express narratives with new and viable object- and meta-discursive rules. A previously accepted use means that keywords are used viably and their use has been established over the course of the session. Narratives contain new object rules or meta-rules when these rules have not been previously established. For example, the utterance "[the multiplication table will repeat itself like that] because 1 modulo 10 is the same as 11 modulo 10, and so on" (Task 2, classroom discussion, Karl, T110-119) expresses a new object rule, namely that numbers can be in the same residue class. At the same time, the keyword "modulo" is used in a previously established way. Centripetal forces have the potential to shift the discourse towards the intended discourse as the eventually-to-be-shared discourse because their metarules and object rules contribute to establishing a tertiary discourse while being accessible to the other students: They are endorsable because they express these rules in line with what has already been established.

Not all utterances exert centripetal or centrifugal forces. Conventional or everyday narratives without a supplementary use of intended keywords or visual mediators are regarded as "neutral," as they do not develop the discourse towards the intended discourse and, without a supplementary use of discursive elements, also do not look as if they were part of the intended discourse.

\section{Methodological Background}

In this study, the third session of a five-session teaching intervention on number theory was investigated. The teaching intervention was located at the very beginning of a oneyear extracurricular transition course taught by the author in 11th grade (90 min per week on Fridays), which is the penultimate school year of upper secondary education in Germany. The penultimate school year is the only option for school-based transition courses, as the last year of upper secondary education is dedicated to the final examination. Still, this course falls within the time frame that Gueudet (2008) defines as transition. The course was implemented and designed by the author, in collaboration at various points with master's students.

\section{Data Collection}

The teaching intervention was taught by the author and videotaped with group-work cameras and a whole-classroom camera. In this section, data from the two group cameras and the whole-classroom discussions will be analyzed. Within the groupwork activities, students explored the patterns in the multiplication table and 
hypothesized about why they occur (Tasks 1 and 2). Here, the students' individualized discourses come to the fore. In the classroom discussions, the students presented their solutions and discussed their viability, so that it became visible how secondary and tertiary utterances are picked up and built upon by other students and the teacher.

\section{Participants}

Fifteen students, aged 15-17, participated voluntarily in the transition course. They came from different mathematics classrooms in the same school. All of the students considered studying STEM subjects at university. The transition course was communicated to them as a chance to engage with university mathematics. Hence, the students were highly motivated and proficient.

\section{Teaching Intervention}

The teaching intervention on elementary number theory was the students' first contact with elementary number theory and with a "different kind" of mathematics, as it represented the first five sessions of the transition course. Because of this, the aims of this intervention on elementary number theory were threefold: First, students were introduced to new practices of hypothesizing and explaining, but not yet to more tertiary practices of defining or proving. Second, the students were introduced to new algebraic structures as a means to build a bridge between familiar elementary/secondary discourses and tertiary discourses. This prepares the students for the subsequent teaching intervention on group theory. Third, the students should be motivated and experience the relevance of the mathematics.

This study was situated in a research program of design research. This research program aims at developing local instruction theories with iterative design experiments that aim at refining hypothetical learning trajectories (Prediger et al. 2015). The present study is a first iteration. Previous research suggests the following cornerstones for a hypothetical learning trajectory in elementary number theory (see Transitions in Elementary Number Theory Section): First, disseminating the differences between modular and elementary notions of numbers in order to avoid mixing up different interpretations (Task 1 of determining patterns in the multiplication table; see below); second, connecting linear congruencies to linear equations in algebra to counteract procedural notions (Task 2 below; see Smith 2006); and third, investigating patterns by means of transparent representations and number examples and going beyond empirical investigations of these patterns with generic examples and algebraizations (all tasks).

The hypothetical learning trajectory addresses transition with a realistic mathematics education (RME) approach. RME posits that context problems are a starting point for students to reinvent mathematics in order to solve the dilemma between informal and formal mathematics (Gravemeijer and Doorman 1999; Gravemeijer 1999). With RME, students can be introduced to tertiary mathematical objects and practices in a meaningful, student-centered way (algebraic groups: Larsen 2013; convergence: Dawkins 2012; practice of proving: Larsen and Zandieh 2008). In this intervention, the intention was for the students to reinvent the discursive objects prime factorization, residue class, and modular addition/multiplication, the latter as reifications of the associated processes (see Sfard 1991; see Table 1). In addition, 
Table 1 Content and aims of the five-session course on modular arithmetic

\begin{tabular}{|c|c|c|c|}
\hline Session & Contents & Aims & $\begin{array}{l}\text { Intended discursive objects } \\
\text { (Focus of the session in bold) }\end{array}$ \\
\hline 1 & $\begin{array}{l}\text { Investigating real-life } \\
\text { problems (calendar dates } \\
\text { and clock times) }\end{array}$ & $\begin{array}{l}\text { Developing a first } \\
\text { understanding of } \\
\text { modular arithmetic }\end{array}$ & $\begin{array}{l}\text { Residue class; } \\
\text { modular addition/ subtraction } \\
\quad \text { (as processes) }\end{array}$ \\
\hline 2 & $\begin{array}{l}\text { Exploring patterns in } \\
\text { modular addition }\end{array}$ & $\begin{array}{l}\text { Exploring differences and } \\
\text { commonalities between } \\
\text { elementary arithmetic and } \\
\text { modular arithmetic }\end{array}$ & $\begin{array}{l}\text { Residue class; } \\
\text { modular addition/ subtraction } \\
\quad \text { (as objects) }\end{array}$ \\
\hline 3 & $\begin{array}{l}\text { Exploring patterns in } \\
\text { modular multiplication, } \\
\text { here, modulo } 10\end{array}$ & $\begin{array}{l}\text { Exploring differences and } \\
\text { commonalities between } \\
\text { elementary arithmetic and } \\
\text { modular arithmetic }\end{array}$ & $\begin{array}{l}\text { Residue class; } \\
\text { modular multiplication } \\
\quad \text { (as object); } \\
\text { prime factorization }\end{array}$ \\
\hline 4 & $\begin{array}{l}\text { Real-life problem: Which } \\
\text { kinds of errors are not } \\
\text { detected by check digits? }\end{array}$ & $\begin{array}{l}\text { Application of } \\
\text { modular arithmetic }\end{array}$ & $\begin{array}{l}\text { Residue class; } \\
\text { modular multiplication; modular } \\
\text { addition (as objects and } \\
\text { processes), linear congruencies }\end{array}$ \\
\hline 5 & $\begin{array}{l}\text { Real-life problem: how to } \\
\text { construct a check digit } \\
\text { that always indicates } \\
\text { transposed digits }\end{array}$ & $\begin{array}{l}\text { Application of } \\
\text { modular arithmetic }\end{array}$ & $\begin{array}{l}\text { Residue class; } \\
\text { modular multiplication; modular } \\
\text { addition (as objects and } \\
\text { processes); linear congruencies }\end{array}$ \\
\hline
\end{tabular}

the learning trajectory was modelled along the object- and meta-level development of discourses, as will be outlined in the next section.

\section{Tasks and Intended Steps in the Learning Trajectory in Session 3}

In the third session of the intervention on elementary number theory investigated in this study, object rules and meta-rules of the discourse initially have a secondary nature, as the students use familiar secondary discourses for working on the tasks. The intent was for the students to develop object rules through reifying processes in modular arithmetic.

- Task 1: The students were asked to fill out the multiplication table modulo 10 (Fig. 1) to uncover patterns and to explain these patterns. The patterns in the multiplication table are connected to the module. To explain these patterns, the students needed to uncover the relations between the composition of the module and the factors of a multiplication (Leuders 2016), that is, formulate object rules of modular multiplication. It was expected, however, that the students would begin by formulating elementary meta-rules of how to do a modular multiplication based on elementary knowledge about multiplication and division with a remainder (see Transitions in Elementary Number Theory Section).

- Task 2: To link linear congruencies to linear equations, Task 2 (Fig. 2) introduced a generic example in which a fictional student Ole tries to justify that the pattern in the second row of the multiplication table is repetitive. The generic example encourages students to look for structures, which is intended to foster the reification 


\section{Explanation of a pattern I}

Ole conjectures that the numbers in the second row will always repeat. He wonders how to show this. He comes up with the following approach:

$$
\begin{aligned}
& 2 \cdot 1=2 \\
& 2 \cdot 2=4 \\
& 2 \cdot 3=6 \\
& 2 \cdot 4=8 \\
& 2 \cdot 5=10 \\
& 2 \cdot 6=2 \cdot(1+5)=2+10 \\
& 2 \cdot 7=2 \cdot(2+5)=4+10 \\
& \vdots
\end{aligned}
$$

What do you think about this approach? Why does it help to explain the pattern in a general way?

\section{Explanation of a pattern II}

Explain that the number pattern in the third row also repeats.

Fig. 2 Tasks 2 and 3 in Session 3 of the teaching intervention on number theory

of modular multiplication into an object by transforming the meta-rules of how to do a modular multiplication into an object.

- Task 3: The students are asked to justify the repetitiveness of the pattern in the third row. Here, students were intended to look beyond the given multiplication table. It was intended that the students would produce a generic example similar to the one in Task 2, while some students might also progress towards an algebraic justification by relating module and factors with prime factorizations. Here, again, metarules of doing a modular multiplication, rooted in elementary discourses, were intended to be transformed into object rules of modular multiplication by looking into the algebraic structures of the multiplication table.

The students worked on Tasks 1 and 2 first in small groups (2-4 students). After that, the solutions to these tasks were presented in the classroom and their viability was discussed. The students then worked on Task 3 in small groups for some minutes (not reported here), which again was followed by a classroom discussion. Next, the smallgroup work in Tasks 1 and 2 and the classroom discussions for Tasks 2 and 3 will be reported (accounts for 85 min of the 90-min session).

\section{Analysis of Data}

In a first step of the analysis, all transcripts were segmented along the individual production of narratives. A segment started with a student taking/getting a turn and continued until the student had produced his or her narrative or until another student took 
over. It was possible that two or more students co-constructed a narrative in one segment and that the teacher was involved in this construction, so that one segment can be assigned to multiple students. For each student, his or her segments were documented in chronological order for each task. Each segment was analyzed in regard to the keywords and the visual mediators and their respective usages and in regard to the produced narratives. Furthermore, each narrative was interpreted in regard to its underlying meta-rules and object rules and whether they were elementary/secondary or tertiary in nature. For each classroom activity - as reported in Tasks and Intended Steps in the Learning Trajectory in Session 3 section - and for each student these rules were synthesized into a metanarrative that gives coherence to this student's production of narratives by identifying the underlying theme. These analytical steps provide insights, via the identified metanarratives, into how individual students proceeded to tertiary discourses and the individual students' perspectives on the eventually-to-be-shared discourse.

In a second step, each segment was analyzed in terms of whether it exerted a centripetal or centrifugal force, in line with the operationalization in the third section. This results in a tabular overview, along the lines of object- and meta-discursive developments (see Appendix), which illustrates the dynamic of how students revisit familiar elementary/ secondary objects in non-viable ways (centrifugal) and how students come to know previous school knowledge in new, tertiary ways (centripetal), which addresses RQ2.

A continuation of centrifugal forces with similar narratives over the $90 \mathrm{~min}$ of the session indicates the existence of a secondary discourse. The continued exertion of centripetal forces together with tertiary object rules and meta-rules and a shared metanarrative indicate a transition towards a unitary tertiary discourse. The comparison of metanarratives gives insight as to whether and to what degree discursants' narratives are related or not. The resulting situational constellations show commognitive conflicts in terms of incompatible developments (RQ1).

\section{Analyses of Learning Processes in Transition}

Appendix Table 3 gives an example that illustrates centripetal and centrifugal forces in the final classroom discussion. Along the horizontal axis, elementary/secondary and tertiary discursive rules are documented, which students enforce in their production of narratives. Along the vertical axis, centrifugal and centripetal forces are documented. The constellations illustrate how the students in the final classroom discussion of the session move towards tertiary object-based narratives (centripetal). At the same time, some students continue to propose variations of elementary/secondary narratives (centrifugal). The comparison of centrifugal and centripetal forces over the course of the investigated teaching session shows that in this final discussion, far less centrifugal force was exerted than before. Additionally, compared with the previous conversations, the students here engaged in conversations about multiples, leading to a substantial number of tertiary narratives exerting centripetal forces. Looking at this table alone, it might seem that Edith was a student who produced both secondary and tertiary narratives, while the other students either produced one or the other. However, these are only tendencies, as the table does not give a full account of all endorsed narratives.

The following three episodes give a fine-grained insight into the dynamics of centrifugal and centripetal forces. These episodes were chosen based on the tabular 
compilation of centripetal and centrifugal forces because they prototypically show how centripetal and centrifugal forces (Appendix Table 3) as well as underlying metanarratives influence each other during discursive developments (Table 2).

\section{Episode 1: Teacher-Guided Classroom Conversation after Working in Groups on Task 2 (Begins with Turn 0, Ends with Turn 122)}

The following episode is located in the classroom conversation about the second task. In this episode, Liam suggests that a repeating pattern can be established in the multiplication table if the number five is systematically subtracted from the numbers in the second half of a non-repeating row.

31 Liam There it is: From 5 onward it simply is with modulo 10 the remainder 0. 32 Teacher Mhm [approving]

33 Liam And in the third, there it is then simply like that there is modulo 5; if one subtracts 5 in this row, then the result is modulo 0 , the same as previously in these rows. Then it repeats.

In T31, Liam repeats an established description of the pattern in the second row. In $\mathrm{T} 33$, he refers to the same position in the multiplication table as in T31, but in the third row with factor 3 instead of factor 2 in the second row. Liam's narrative is endorsable without the keyword "modulo" in the form "that there is 5" and "there results the

Table 2 Endorsed metanarratives over the course of the analyzed intervention session

\begin{tabular}{|c|c|}
\hline Activity & $\begin{array}{l}\text { Endorsed metanarratives } \\
\text { ("we" indicates that it is endorsed by at least two students) }\end{array}$ \\
\hline Group work on Task 1 & $\begin{array}{l}\text { Group Edith and John: } \\
\text { We search for geometric and numeric properties } \\
\text { in the multiplication table. } \\
\text { Group Carl, Lawrence, and Ludwig: } \\
\text { We search for number patterns (and sometimes geometric patterns) in the } \\
\quad \text { multiplication table. }\end{array}$ \\
\hline Group work on Task 2 & $\begin{array}{l}\text { Group Edith and John: } \\
\text { We search for rules to describe repeating patterns } \\
\quad \text { with the distributive law. } \\
\text { Group Carl, Lawrence, and Ludwig: } \\
\text { We try to describe the emergence of patterns } \\
\text { in the multiplication table. }\end{array}$ \\
\hline Classroom conversation on Task 2 & $\begin{array}{l}\text { Metanarrative } 1 \text { (shared by Edith, Lawrence, Ludwig, and Karl): } \\
\text { We search for underlying structures to explain the repeating } \\
\text { patterns, with a focus on both the distributive law } \\
\text { and the multiplication table. } \\
\text { Metanarrative } 2 \text { (Shared by Petra and Liam): } \\
\text { We search for further patterns in the multiplication table. }\end{array}$ \\
\hline Classroom conversation on Task 3 & $\begin{array}{l}\text { Metanarrative } 1 \text { (shared by Edith, Lawrence, and Ludwig): } \\
\text { We explain the patterns in the multiplication table. } \\
\text { Metanarrative } 2 \text { (shared by Petra, Norwig, and Max): } \\
\text { We search and try to establish new repeating patterns, } \\
\text { while allowing the module to change. }\end{array}$ \\
\hline
\end{tabular}


same," which means that this keyword is used supplementary. Furthermore, the way Liam uses "modulo" indicates that modulo is an operator.

The narrative Liam produces is elementary, as it is about the elementary operation of subtracting 5 from numbers in the multiplication table. Liam's narratives enforce two non-viable rules. First, he puts forward the object rule that modulo is an operator. Second, he introduces - for the first time in this third intervention session - the metarule that the multiplication table is a carrier of numbers on which one can operate in order to establish new patterns. While this may be a variation of elementary rules of operating on elementary numbers, it changes how the visual mediator multiplication table is used in the classroom discourse, because previously its numbers were correctly treated as not changeable. Nevertheless, the metanarrative behind Liam's production of narratives is the search for patterns in the multiplication table, which is in this form endorsed by the other discursants.

Taken together, the secondary, non-viable narrative and the supplementary use of modulo exert a centrifugal force. The supplementary use of modulo signalizes to the other discursants that Liam's narrative is endorsable, as it appears to fit the intended discourse. Additionally, as his narrative is close to familiar discourses - changing the multiplication table with elementary operations may be plausible to the other discursants - it might also be relatively easy to endorse. As Liam is exploring new ways of using the multiplication table, his utterance exerts a centrifugal force, because his proposed new way of using the multiplication table appears to the other discursants as belonging to the eventually-to-be-shared discourse, as it follows a metanarrative in line with the shared meta-rule of searching for patterns in the multiplication table.

\section{Episode 2: Task 3, Teacher-Guided Classroom Conversation after Working in Groups on Task 3 (Begins with Turn 0, Ends with Turn 108)}

In the classroom discussion about the third task, centrifugal forces push the discourse towards changing the module of modular multiplication. The following conversation (edited for brevity and clarity) is about whether a modular multiplication modulo 15 would have similar patterns as the one modulo 10, but in rows with uneven factors instead of even factors.

30 Petra $\quad$. . If one would calculate with modulo 15, if that would exchange places with the even ones? I mean with the uneven ones simply from 5 on the rows would repeat, because with the even numbers [it would repeat] from 10 ?

31 Teacher Interesting question.. .. But I believe if we get behind this [points at the multiplication table on the projector] we will have an answer to your question.

32 Edith Can I say something to that?

33 Teacher Yes, if it contributes to this [points at multiplication table]. Yes.

34 Edith Yes, so I would say that that is not correct, because the repetition would not change. It only changes like how one goes. It is a different approach, but the repetition of the numbers would not change. That means, only because you are in a different modulo it can't be that the multiplication of the same numbers changes.. . .

40 Norwig Ok, [I want to add] to that as well. 
41 Teacher Mhm. Yes, okay.

42 Norwig So, one sees that with 1, 3, 5, 7, 9 there is always a 5 [teacher approves]. That's why it would work as well. It is logical, because we already said that if you subtract 5 from $6,7,8,9$, and 10,1 would be in the same row. This is logical.

Both Petra's (T30) and Edith's (T34) utterances exert a centrifugal force in the classroom conversation. The use of "modulo" as a label suggests to the other discursants that the utterances are in line with the intended discourse. At the same time, the narratives are secondary in nature: They are a variation of the discourse on patterns of natural numbers and on even and odd numbers. This makes them endorsable by the others. Hence, these utterances push the conversation towards a non-intended secondary discourse while looking like it is in line with the intended tertiary discourse. And indeed, Norwig endorses Petra's and Edith's narratives (T42). He suggests that the patterns in the multiplication table would change with a changing module. Notably, with his utterance, Norwig seems to also endorse the centrifugal narrative from Liam in Episode 1, where the object rule that the entries in the multiplication table can be changed was put forward. This illustrates how Norwig, under the centrifugal forces from both Episodes 1 and 2 may have been pushed towards non-viable narratives which seem to be variations of narratives from elementary/secondary discourses on elementary subtraction and elementary patterns of the order of natural numbers.

The individual metanarratives in this episode suggest an underlying commognitive conflict (see overview of metanarratives in Table 2). Petra's and Norwig's narratives share the meta-rule that the module can be changed in order to uncover new patterns. Beyond that, Norwig seems to take up Liam's extended metanarrative from Episode 1 and suggests that the entries in the multiplication table can be operated upon. Edith, on the other hand, shares the metanarrative of finding new patterns, but does not endorse the change of the module. Instead, she seems to relate the multiplication table to the number line. Hence, in this episode, the three students all produce narratives about the same issue, and seemingly are communicating with each other, but the discourses they pursue share similar yet different metanarratives that set Liam's and Petra's discourses in conflict with Edith's.

\section{Episode 3: Task 3, Teacher-Guided Classroom Conversation after Working in Groups on Task 3 (Begins with Turn 0, Ends with Turn 108)}

In the following episode from the final classroom conversation, centripetal forces push the classroom discourse towards the intended tertiary discourse. Ludwig tries to explain why the second row of the multiplication table with factor 2 is repeating, while the third is not.

6 Ludwig I wrote it down like this [partly reads from his worksheet]: If the remainder of a number $x$ is 0 , I mean if at a number $x$ the remainder is 0 [teacher approves, T8], so now at the 1 it would be at 0 , with 2 it would be at 5 , with 3 it would again be 10 [teacher approves, T10], then a repeating pattern would occur, because with the help of the distributive law the number $x$, or a multiple of the number $x$, no, no, the number $y$ [teacher approves, T12] because the number $y$ or a multiple of the number $y$ can be separated [from it]. 
In his explanation, Ludwig uses the keywords "remainder" and "multiple" in viable ways, and these keywords have a relevant role, as his utterance would not be viable without them. Furthermore, Ludwig's explanation is a narrative with new object rules and metarules. In this case, Ludwig establishes the object rule "a repeating pattern occurs, if at a factor $y$ the remainder is 0 , and hence, with the distributive law the multiplication can be split." This object rule implicitly assumes a prime factorization: It is tertiary. Thus, this explanation has the potential to pull the conversation towards the intended tertiary discourse.

Ludwig's narrative is the most elaborate one in this session. The underlying metanarrative is "explaining the patterns" but elaborated with the object rule that "the result modulo 0 can be traced back to common factors of the product and the module." This metanarrative is in line with the prime factorization of numbers, and, hence, with the intended tertiary discourse. As a result, Ludwig's utterance exerts a centripetal force towards the intended discourse in this conversation because of its use of keywords and the novel tertiary object rule about common factors.

\section{Centripetal and Centrifugal Forces in the Development of the Classroom Discourse}

The centrifugal forces, here illustrated in Episodes 1 and 2, indicate not a discursive development, but an extension of secondary discourses with variations of longendorsed elementary narratives about the processes of multiplication, division, and the objects of even and odd numbers. These narratives culminate in the idea of changing the multiplication table (Liam, T30, Phase 3) or the module to establish new patterns (Petra, T30, Phase 4). They show that there is a secondary discourse in this classroom that remains within established secondary object rules and meta-rules. The continued activation of centrifugal forces over the whole session suggests that this discourse lasts the whole third session of the intervention (see Appendix Table 3).

The centripetal forces indicate a discursive development in a parallel discourse. This becomes evident in the final classroom conversation, here illustrated by Episode 3 and Appendix Table 3, where some students explore new object rules that are based on the idea of multiples. The idea of multiples originates in the group work in Task 2 (Karl, T26, Phase 2)-relatively early in Session 3-but is only now endorsed. These narratives can be regarded as a first step into tertiary object rules of elementary number theory. They require the reorganization of secondary/elementary narratives, especially the reorganization of the object rules of elementary operations.

\section{Central Contributions and Discussion}

This study investigates the conditions and affordances under which students come to know their previous school knowledge in new, tertiary ways in an upper-secondary transition course. It contributes to the examination of the problem of students' continuing secondary discourses in tertiary mathematics (Thoma and Nardi 2017; Nardi et al. 2014; Stadler 2011). By adding the constructs of metanarrative (Lyotard 1984) and heteroglossia (see Bakhtin 1981) to Sfard's (2008) discursive perspective, this study was able to investigate the secondary-tertiary tradition from a learning processes perspective, with a focus on students' perspectives and students' ways of constructing narratives between familiar elementary/secondary discourses and the intended tertiary discourse. 
With respect to RQ1, this study finds a commognitive conflict of the eventually-tobe-shared discourse. This commognitive conflict describes conflicts in communication that result from two discourses developing in parallel in the classroom: the intended tertiary discourse and a variation of elementary and/or secondary discourses. On the one hand, the students are not "of one mind with regard to whose discourse is to be eventually shared" (Sfard 2015, p. 136), because two discourses with different developmental trajectories coexist in the classroom. On the other hand, these two discourses are still linked with a common metanarrative, as shown above in Episodes 1-3. Hence, in the commognitive conflict of the eventually-to-be-shared discourses, the students try to communicate over two discourses, which are perceived as the same by them. For the students, this might seem feasible because of a shared metanarrative. However, as the meta-rules and object rules of the two discourses differ, the discursants' attempts at communicating across the discourses lead to conflicts. One example is the two ways students use the multiplication table (Fig. 1) in these two discourses, either as a changeable object in the secondary discourse or as an algebraic structure in the discourse of modular multiplication (see Episode 2). Another example is Ludwig's contribution in Episode 3. Ludwig's utterance is located in the evolving tertiary discourse. The teacher's invitation for new explanations based on Ludwig's contribution, however, again leads into the other elementary/secondary discourse, perhaps because this discourse is more accessible, as it builds on familiar elementary discursive rules. As a result, Ludwig's contribution is not picked up by others.

With respect to RQ2, two main drivers for this commognitive conflict have been identified. The first driver is a metanarrative (Lyotard 1984) of "we search for and explain patterns," which is shared but individually elaborated by both the proponents of tertiary discourses and of secondary discourses. Metanarratives are narratives that define patterns in the students' activities of producing narratives. The shared metanarrative allows for the production of a wide range of narratives, which can lead both to the intended discourse as a centripetal force (e.g., "multiples of 2 as a factor are a prerequisite for patterns") and to non-viable narratives as a centrifugal force (e.g., "subtracting 5 from a number of entries in the multiplication table to generate new patterns"). For the proponents of the different narratives and, ultimately, of the two different discourses, this metanarrative seems to act as a fallback narrative that is used to make one's narratives understandable to the others. This explains why the students can still communicate with each other in the final classroom discussion: Edith is even able to contribute to the two discourses, despite them being incommensurable. The second driver is centrifugal forces. Student utterances can exert a centrifugal force towards continuing secondary discourses when they use elements of the intended tertiary discourse (such as keywords and visual mediators) in a supplementary way to express elementary/secondary, everyday, or non-viable narratives. For example, students use the word modulo in narratives about elementary multiplication superfluously; that is, the narrative is an endorsable elementary narrative without the word modulo. Thus, the keyword modulo, albeit tertiary, does not add to the discourse's development to a tertiary discourse. Instead, it perpetuates already accepted school mathematical discourses and even adds non-viable narratives to it.

The results of this study suggest that changing or addressing metanarratives is relevant in transition. In the context of argumentation, it has been argued that a "shared basis of agreement" regulates the flow of a proof, i.e., the steps in a proving process, so 
that students need an awareness of it (Gabel and Dreyfus 2016). Here, metanarratives are an enabling factor of the parallel development of tertiary and secondary discourse in that they allow for patterned activities that can be either elementary/secondary or tertiary in nature. It might be that rituals - teacher-modelled or -guided patterned communicative activities - can give students a clearer picture of intended metanarratives (Lavie et al. 2018). However, ritual teaching might not be compatible with the guided reinvention approach employed here, which gives students more agency. Alternatively, materializing tertiary utterances such as Ludwig's in Episode 3 can foster rituals of "observing" and "imitating" the intended tertiary discourse (Sfard 2014) and its metanarratives. Similarly, expert narratives such as a textbook mathematical definition embody tertiary narratives and rules (see Zandieh and Rasmussen 2010), so that exposing students to these might provide students with insights into tertiary metanarratives. Students might benefit from such a regulated alienation after they have explored a given problem with their elementary and secondary mathematical knowledge. Finally, engaging students in inquiry-based learning might challenge their metanarratives. In inquiry-based learning, students participate in communicative actions of posing questions, conjecturing, hypothesizing, and justifying or refuting hypotheses (Artigue and Blomhøj 2013). Treating students' narratives as conjectures and hypotheses could foster exploratory talk and possibly an awareness of the insufficiency of elementary/secondary narratives.

Future studies of learning processes in transition should investigate how the commognitive conflict of the eventually-to-be-shared discourse affects student learning over a longer period of time. For example, is the parallel development of elementary/secondary and tertiary discourses found here an indicator of an incremental and evolutionary discursive development where a long adherence to school discourses is needed to build foundations for creating new tertiary narratives, which then follow incrementally? Or is discursive development instead revolutionary, driven by students who act as "agents of change" (see Hershkowitz et al. 2014) who start to engage in conversations with tertiary objects by leaving behind previous secondary narratives, as Ludwig in this study? How then do students become agents of change? Furthermore, this study does not directly account for the teacher's influence on discursive development. Within the students' guided reinvention of objects of elementary number theory, the teacher's intended role was to be a moderator. The students were intended to engage in exploratory talk, that is, to make proposals and critically build on each other's ideas (Mercer 1996). However, as Episode 2 illustrates, in the end of the teaching session, the students engaged in cumulative talk, where ideas were repeated, elaborated, and confirmed. This might be a result of the shared metanarrative of finding patterns in the multiplication table, which could have made the students uncritical of each other's ideas because they might have believed they were of one mind about the eventually-to-be-shared discourse. Hence, studies are needed which investigate the role of the teacher in scaffolding discursive developments in transition.

\section{Compliance with Ethical Standards}

Conflict of Interest Statement The author states that there is no conflict of interest. 


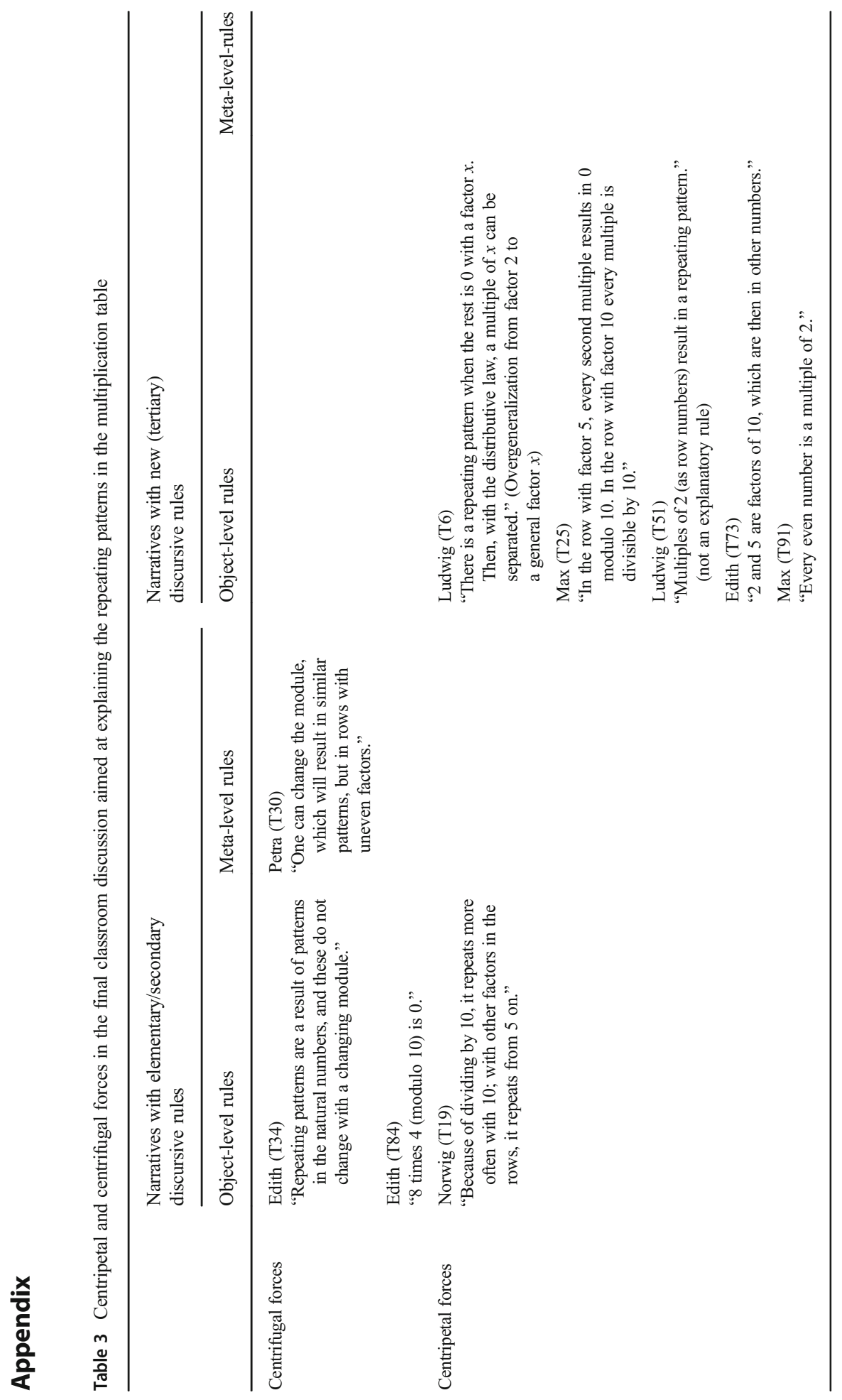


Open Access This article is distributed under the terms of the Creative Commons Attribution 4.0 International License (http://creativecommons.org/licenses/by/4.0/), which permits unrestricted use, distribution, and reproduction in any medium, provided you give appropriate credit to the original author(s) and the source, provide a link to the Creative Commons license, and indicate if changes were made.

Publisher's Note Springer Nature remains neutral with regard to jurisdictional claims in published maps and institutional affiliations.

\section{References}

Alcock, L., \& Simpson, A. (2002). Definitions: Dealing with categories mathematically. For the Learning of Mathematics, 22(2), 28-34.

Artigue, M., \& Blomhøj, M. (2013). Conceptualizing inquiry-based education in mathematics. ZDM Mathematics Education, 45(6), 797-810. https://doi.org/10.1007/s11858-013-0506-6.

Bakhtin, M. M. (1981). The dialogic imagination: Four essays. Austin: University of Texas Press.

Campbell, S. R. (2002). Coming to terms with division: Preservice teachers understanding. In S. R. Campbell $\&$ R. Zazkis (Eds.), Learning and teaching number theory: Research in cognition and instruction (pp. 1540). Westport: Ablex Publishing.

Dawkins, P. C. (2012). Metaphor as a possible pathway to more formal understanding of the definition of sequence convergence. The Journal of Mathematical Behavior, 31(3), 331-343. https://doi.org/10.1016/j. jmathb.2012.02.002.

De Guzmán, M., Hodgson, B. R., Robert, A., \& Villani, V. (1998). Difficulties in the passage from secondary to tertiary education. In G. Fischer \& U. Rehmann (Eds.), Proceedings of the International Congress of Mathematicians (Vol. III, pp. 747-762). Berlin: Documenta Mathematica.

de Oliveira, G. P. (2015). Numerical representations and technologies: possibilities from a configuration formed by teachers-with-GeoGebra. Educação Matemática Pesquisa, 17(5), 897-918.

Gabel, M., \& Dreyfus, T. (2016). Affecting the flow of a proof by creating presence - a case study in number theory. Educational Studies in Mathematics, 96(2), 187-205. https://doi.org/10.1007/s10649-016-9746-z.

Gravemeijer, K. (1999). How emergent models may foster the constitution of formal mathematics. Mathematical Thinking and Learning, 1(2), 155-177.

Gravemeijer, K., \& Doorman, M. (1999). Context problems in realistic mathematics education: a calculus course as an example. Educational Studies in Mathematics, 39(1-3), 111-129.

Gueudet, G. (2008). Investigating the secondary-tertiary transition. Educational Studies in Mathematics, 67(3), 237-254.

Hershkowitz, R., Tabach, M., Rasmussen, C., \& Dreyfus, T. (2014). Knowledge shifts in a probability classroom: a case study coordinating two methodologies. ZDM Mathematics Education, 46(3), 363387. https://doi.org/10.1007/s11858-014-0576-0.

Iatridou, M., \& Papadopoulos, I. (2010). From area to number theory: A case study. In V. Durand-Guerrier, S. Soury-Lavergne, \& F. Arzarello (Eds.), Proceedings of the 6th conference of European research in mathematics education (pp. 599-608). Lyon: Institut national de recherche pédagogique.

Larsen, S. P. (2013). A local instructional theory for the guided reinvention of the group and isomorphism concepts. The Journal of Mathematical Behavior, 32(4), 712-725. https://doi.org/10.1016/j.jmathb.2013.04.006.

Larsen, S., \& Zandieh, M. (2008). Proofs and refutations in the undergraduate mathematics classroom. Educational Studies in Mathematics, 67(3), 205-216. https://doi.org/10.1007/s10649-007-9106-0.

Lavie, I., Steiner, A., \& Sfard, A. (2018). Routines we live by: from ritual to exploration. Educational Studies in Mathematics (online first). https://doi.org/10.1007/s10649-018-9817-4.

Leuders, T. (2016). Erlebnis Algebra. Zum aktiven Entdecken und selbstständigen Erarbeiten [Experience Algebra. For active reinvention and self-preparation]. Berlin, Heidelberg: Springer Spektrum.

Lyotard, J. F. (1984). The postmodern condition: A report on knowledge. Manchester: Manchester University Press.

Mercer, N. (1996). The quality of talk in Children's collaborative activity in the classroom. Learning and Instruction, 6(4), 359-377.

Morselli, F. (2006). Use of examples in conjecturing and proving: An exploratory study. In J. Novotná, H. Moraová, M. Krátká, \& Stehlíková (Eds.), Proceedings 30th conference of the International Group for the Psychology of mathematics education (pp. 185-192). Prague: PME.

Nardi, E., Ryve, A., Stadler, E., \& Viirman, O. (2014). Commognitive analyses of the learning and teaching of mathematics at university level: the case of discursive shifts in the study of Calculus. Research in Mathematics Education, 16(2), 182-198. https://doi.org/10.1080/14794802.2014.918338. 
Papadopoulos, I., \& Iatridou, M. (2010). Modelling problem-solving situations into number theory tasks: The route towards generalisation. Mathematics Education Research Journal, 22(3), 85-110.

Praslon, F. (1999). Discontinuities regarding the secondary/university transition: the notion of derivative as specific case. In O. Zaslavsky (Ed.), Proceedings of the 23rd international conference on the psychology of mathematics education (pp. 73-80). Haifa: Technion-Israel Institute of Technology.

Prediger, S., Gravemeijer, K., \& Confrey, J. (2015). Design research with a focus on learning processes: an overview on achievements and challenges. ZDM Mathematics Education, 47(6), 877-891. https://doi. org/10.1007/s11858-015-0722-3.

Schüler-Meyer, A. (2018). Defining as discursive practice in transition-Upper secondary students reinvent the formal definition of convergent sequences. In V. Durand-Guerrier, R. Hochmuth, S. Goodchild, \& N. M. Hogstad (Eds.), Proceedings of INDRUM 2018 - second conference of the international network for didactic research in university mathematics (pp. 537-546). Kristiansand: University of Agder and INDRUM.

Selden, A. (2012). Transitions and proof and proving at tertiary level. In G. Hanna \& M. de Villiers (Eds.), Proof and proving in mathematics education (pp. 391-420). Dordrecht: Springer. https://doi.org/10.1007 /978-94-007-2129-6_17.

Sfard, A. (1991). On the dual nature of mathematical conceptions: Reflections on processes and objects as different sides of the same coin. Educational Studies in Mathematics, 22(1), 1-36. https://doi.org/10.1007/BF00302715.

Sfard, A. (2008). Thinking as communicating: Human development, the growth of discourses, and mathematizing. New York: Cambridge University Press.

Sfard, A. (2014). University mathematics as a discourse - why, how, and what for. Research in Mathematics Education, 16(2), 199-203. https://doi.org/10.1080/14794802.2014.918339.

Sfard, A. (2015). Learning, commognition and mathematics. In D. Scott \& E. Hargreaves (Eds.), The sage handbook of learning (pp. 129-138). London: Sage.

Smith, J. C. (2006). Revisiting algebra in a number theoretical setting. In R. Zazkis \& S. R. Campbell (Eds.), Number theory in mathematics education: Perspectives and prospects (pp. 249-283). London: Routledge.

Stadler, E. (2011). The same but different-novice university students solve a textbook exercise. In M. Pytlak, T. Rowland, \& E. Swoboda (Eds.), Proceedings of the 7th conference of European researchers in mathematics education (pp. 2083-2092). Rzeszów: University of Rzeszów.

Tall, D. (1991). The psychology of advanced mathematical thinking. In D. Tall (Ed.), Advanced mathematical thinking (pp. 3-21). New York: Kluwer Academic.

Thoma, A. \& Nardi, E. (2017). Discursive shifts from school to university mathematics and lecturer assessment practices: Commognitive conflict regarding variables. To be published in: Proceedings of the 10th congress of the European society for research in mathematics education, Dublin.

Thomas, M. O. J., de Freitas Druck, I., Huillet, D., Ju, M.-K., Nardi, E., Rasmussen, C., \& Xie, J. (2015). Key mathematical concepts in the transition from secondary school to university. In S. J. Cho (Ed.), The proceedings of the 12th international congress on mathematical education (pp. 265-284). Cham: Springer International Publishing. https://doi.org/10.1007/978-3-319-12688-3_18.

Toh, P. C., Leong, Y. H., Toh, T. L., \& Ho, F. H. (2014). Designing tasks for conjecturing and proving in number theory. In C. Nicol, S. Oesterle, \& P. Liljedahl (Eds.), Proceedings of the Joint Meeting 5-257 of PME 38 and PME-NA 36 (pp. 257-265). Vancouver: PME.

Zandieh, M., \& Rasmussen, C. (2010). Defining as a mathematical activity: a framework for characterizing progress from informal to more formal ways of reasoning. The Journal of Mathematical Behavior, 29(2), 57-75. https://doi.org/10.1016/j.jmathb.2010.01.001.

Zazkis, R. (1998). Odds and ends of odds and evens: an inquiry into students' understanding of even and odd numbers. Educational Studies in Mathematics, 36(1), 73-89.

Zazkis, R. (2002). Language of number theory: Metaphor and rigor. In S. R. Campbell \& R. Zazkis (Eds.), Learning and teaching number theory: Research in cognition and instruction (pp. 83-95). Westport: Ablex.

Zazkis, R. (2007). Number theory in mathematics education: Queen and servant. In J. Novotna \& H. Moraova (Eds.), Proceedings of the international symposium elementary mathematics teaching SEMT '07 (pp. 4659). Prague: Charles University.

Zazkis, R. (2011). Relearning mathematics: A challenge for prospective elementary school teachers. Charlotte: Information Age.

Zazkis, R., \& Campbell, S. R. (1996). Divisibility and multiplicative structure of natural numbers: preservice teachers' understanding. Journal for Research in Mathematics Education, 27(5), 540-563.

Zazkis, R., \& Campbell, S. R. (2006). Number theory in mathematics education research: Perspectives and prospects. In R. Zazkis \& S. R. Campbell (Eds.), Number theory in mathematics education: Perspectives and prospects (pp. 1-17). Mahwah: Lawrence Erlbaum Associates.

Zazkis, R., \& Gadowsky, K. (2001). Attending to transparent features of opaque representations of natural numbers. In A. Cuoco (Ed.), The roles of representation in school mathematics (pp. 44-52). Reston: NCTM. 